\title{
MAPEAMENTO DIGITAL DOS ASPECTOS FíSICOS DA MESORREGIÃO DO TRIÂNGULO MINEIRO, ATRAVÉS DOS SOFTWARES AUTOCADR12 E GRASS 4.0
}

\author{
Celso Antônio de Siqueira \\ Geógrafo do Dep. de Geografia - UFU \\ Roberto Rosa \\ Prof. Dr. do Dep. de Geografia - UFU
}

RESUMO: O objetivo básico deste trabalho voltou-se à confecção de mapas temáticos relacionados aos condicionantes do meio físico da Mesorregião do Triângulo Mineiro, através do processo digital, cuja elaboração se deu em função das grandes transformações espaciais ocorridas no seu meio físico natural, em decorrência da alteração das formas de uso e ocupação do solo promovidas pelo processo de desenvolvimento econômico acelerado das três últimas décadas. Para sua execução foram utilizados os softwares AutoCADR12, na digitalização e apresentação final dos mapas e GRASS 4.0, na efetuação dos cálculos de áreas de cada mapa temático e no cruzamento de dados. $O$ uso dos referidos softwares permitiu alcançar bons resultados para o objetivo proposto.

Palavras Chaves: cartografia digital, mapas temáticos, meio físico.

ABSTRACT: This paper aims to describe the elaboration of thematic maps, referring to the Physical aspects of Triângulo Mineiro - MG, using the softwares AutoCADr12 and Grass 4.0, considering the great spatial transformation occured in the referred region in the last three decades. For its execution the softwares AutoCADR12 were used in the digitalization and presentation of the maps and GRASS 4.0, in the effectuation of calculations of areas of each thematic map and in the crossing of data. The use of the referred softwares allowed to reach good results for the proposed objective.

Key Words: digital cartography, thematic maps, physical aspects.

\section{1 - INTRODUÇÃo}

O constante avanço da tecnologia computacional e a conseqüente utilização do processo digital tem revolucionado a produção de material cartográfico e se traduzido na forma mais eficaz para a produção de mapas. $O$ processo digital imprime maior fidelidade, qualidade e legibilidade às informações cartografadas, oferecendo uma gama muito maior de recursos (facilidade de armazenamento, manipulação, consulta e tratamento das informações).
O processo digital tem facilitado a produção de material cartográfico e contemplado os mais diversos aspectos de uma determinada região, tanto no que diz respeito ao meio físico quanto ao sócioeconômico, tornando-se de fundamental importância para o entendimento de suas interrelações e transformações.

O objetivo deste trabalho é o mapeamento digital dos aspectos físicos da Mesorregião do Triângulo Mineiro, através da utilização dos softwares AutoCADR12 e 
GRASS 4.0, visando o agrupamento de importantes informações sobre a área de estudo e que poderão servir de subsídio ao estudo básico da região, contemplando, inclusive, conteúdos a nível de $1^{\circ}$ e $2^{\circ}$ graus em temas diversificados, como: divisão política, subbacias hidrográficas, geologia, geomorfologia, hipsometria, declividade, solos, uso da terra, temperatura média anual e precipitação anual.

\section{2 - A ÁREA DE ESTUDO}

A Mesorregião do Triângulo Mineiro ocupa uma área de $52.760 \mathrm{~km}^{2}$, situada no extremo oeste do Estado de Minas Gerais, entre as coordenadas $18^{\circ} 00^{\prime}$ e $20^{\circ} 30^{\prime} \mathrm{S}$ e $47^{\circ} 30^{\prime} \mathrm{e}$ $51^{\circ} 15^{\prime} \mathrm{W}$. Conforme NISHIYAMA \& BACCARO (1989), quase a totalidade da região situa-se numa área de cobertura magmáticosedimentar, pertencente à Bacia Sedimentar do Paraná. Sua morfologia é constituída por imensas superfícies aplainadas que cortam as rochas cristalinas e sedimentares, dando forma aos extensos chapadões de topos aplainados e quase sempre limitados pelas escarpas erosivas, resultantes da erosão diferencial entre as formações Marília e Adamantina ou mantidas pelos derrames basálticos, como ocorre nas bordas das vertentes voltadas para os rios Araguari, Paranaíba e Grande. Nas áreas de topo essas chapadas apresentam interflúvios amplos e largos, com vales espaçados entre si, pouca ramificação da drenagem e vertentes com declividades baixas, que variam entre 5 e $9 \%$.

A referida região possui também uma malha viária considerável, que a coloca como intermediadora das outras regiões do país. Além disto, o fato de estar localizada entre o Estado de São Paulo, principal centro industrial do país, e o Estado de Goiás, com índices bastante representativos na agropecuária nacional, contribuiu decisivamente para que a região atingisse um nível de desenvolvimento econômico bastante acelerado, principalmente nos últimos vinte e cinco anos.

\section{3 - MATERIAIS}

Para realização do presente trabalho utilizaram-se os seguintes materiais $e$ equipamentos dos Laboratórios de Geoprocessamento e de Cartografia e Sensoriamento Remoto do Departamento de Geografia da Universidade Federal de Uberlândia:

- microcomputadores;

- mesa digitalizadora;

- impressoras;

- imagens de satélite TM/LANDSAT coloridas, em papel, escala 1:100.000;

- cartas topográficas do FIBGE, escala 1:100.000;

- mapas temáticos do Projeto RADAMBRASIL Folha SE-22 / Goiânia, escala 1:1.000.000;

- mapa geográfico de Minas Gerais - IGA, 1983 $(1: 500.000)$;

- softwares AutoCADR12, WinWord 6.0 e GRASS 4.0.

\section{4 - METODOLOGIA}

A execução do presente trabalho seguiu basicamente as seguintes etapas:

- análise bibliográfica de estudos sobre os aspectos físicos da região e coleta de dados;

- elaboração do mapa-base, extraído do Mapa Geográfico de Minas Gerais - IGA/1983 na escala de 1:500.000;

- compilação dos mapas temáticos do projeto RADAMBRASIL (1983) e atualização com o uso de imagens de satélite TM/LANDSAT;

- digitalização, edição e impressão dos mapas, através do software AutoCADR12;

- cálculos de área e cruzamento de informações dos mapas temáticos: uso da terra, solos e declividade, através do software GRASS 4.0. 


\section{5 - ANÁLISE DOS MAPAS}

\section{1 - Divisão Política}

Conforme o exposto anteriormente, na sua elaboração utilizou-se a base extraída do Mapa Geográfico de Minas Gerais (IGA, 1983), na escala de 1:500.000. Nesse mapa estão reproduzidos os limites interestaduais, os limites intermunicipais, as cidades-sedes dos trinta e um (31) municípios que compõem a Mesorregião do Triângulo Mineiro, as principais rodovias asfaltadas e não asfaltadas, a linha ferroviária que corta a parte leste da área de estudo e, finalmente, constam também os grandes lagos formados pelas represas de Emborcação, Itumbiara, Cachoeira Dourada e São Simão, no rio Paranaíba; e Volta Grande,
Porto Colômbia, Marimbondo e Água Vermelha, no rio Grande, onde estão localizadas as respectivas Usinas Hidrelétricas (Mapa 1).

O quadro 1 mostra os nomes dos municípios, a extensão em $\mathrm{Km}^{2}$ e também a porcentagem que cada um deles representa em relação à área total da Mesorregião do Triângulo Mineiro. Conforme se pode verificar, o município do Prata é o que possui maior área, com 4.760 $\mathrm{Km}^{2}$, que representa $9,02 \%$ da área total, seguido pelos municípios de Uberaba, com $4.524 \mathrm{Km}^{2}$ ou $8,57 \%$ e Uberlândia, com 4.040 $\mathrm{Km}^{2}$ ou $7,65 \%$ do total da área. As menores são as áreas dos municípios de Cachoeira Dourada, com $208 \mathrm{Km}^{2}$ ou $0,39 \%$ e Fronteira, com $231 \mathrm{Km}^{2}$ ou $0,43 \%$ do total da área.

Quadro 1 - Área ocupada pelos vários municípios

\begin{tabular}{|c|c|c|}
\hline Muntoriso & $\mathrm{K} \mathrm{m}^{2}$ & $\%$ \\
\hline 1. Água Comprida & 447 & 0,85 \\
\hline 2. Araguari & 2.774 & 5,26 \\
\hline 3. Araporā & 291 & 0,55 \\
\hline 4. Cachoeira Dourada & 208 & 0,39 \\
\hline 5. Campina Verde & 3.706 & 7,02 \\
\hline 6. Campo Florido & 1.324 & 2,51 \\
\hline 7. Canápolis & 913 & 1,73 \\
\hline 8. Capinópolis & 697 & 1,42 \\
\hline 9. Carneirinho & 2.005 & 3,80 \\
\hline 10. Centralina & 354 & 0,67 \\
\hline 11. Comendador Gomes & 1.085 & 2,05 \\
\hline 12. Conceição das Alagoas & 1.292 & 2,44 \\
\hline 13. Conquista & 646 & 1,22 \\
\hline 14. Fronteira & 231 & 0,43 \\
\hline 15. Frutal & 2.391 & 4,53 \\
\hline 16. Gurinhatã & 2.040 & 3,86 \\
\hline 17. Ipiaçu & 443 & 0,84 \\
\hline 18. Itapagipe & 1.811 & 3,43 \\
\hline 19. Ituiutaba & 2.694 & 5,10 \\
\hline 20. Iturama & 2.542 & 4,82 \\
\hline 21. Limeira do Oeste & 1.299 & 2,46 \\
\hline 22. Monte Alegre & 2.695 & 5,10 \\
\hline 23. Pirajuba & 344 & 0,65 \\
\hline 24. Planura & 337 & 0,63 \\
\hline 25. Prata & 4.760 & 9,02 \\
\hline 26. Santa Vitória & 2.951 & 5,59 \\
\hline 27. São Francisco de Sales & 1.048 & 1,98 \\
\hline 28. Tupaciguara & 1.704 & 3,23 \\
\hline 29. Uberaba & 4.524 & 8,57 \\
\hline 30. Uberlândia & 4.040 & 7,65 \\
\hline 31. Veríssimo & 1.164 & 2,20 \\
\hline TOTAL & 52.760 & 100,00 \\
\hline
\end{tabular}

Fonte: Anuário Estatístico de Minas Gerais - 1995 


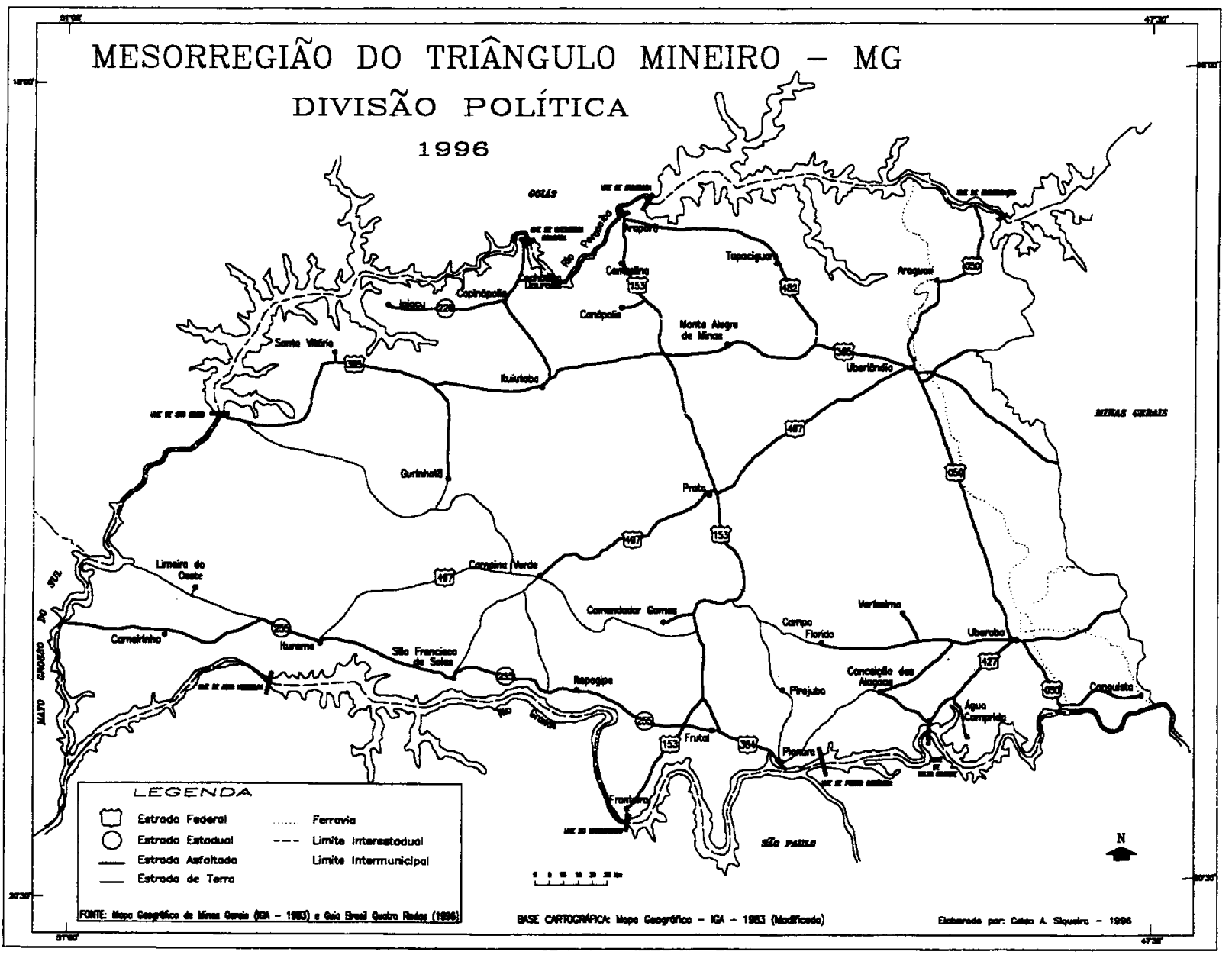

\section{2 - Sub-bacias hidrográficas}

O mapa de drenagem também foi produzido a partir do Mapa Geográfico de Minas Gerais (IGA,1983), e nele estão representados os rios mais importantes, os seus afluentes e a delimitação das suas respectivas sub-bacias. São os seguintes rios: Tijuco, Arantes, Verde ou Feio, Araguari, Uberaba, Piedade e São Francisco (Quadro 2, Mapa 2). 
Quadro 2 - Área ocupada pelas diferentes sub-bacias

\begin{tabular}{|c|c|c|}
\hline SUB-BAOLA & $\mathrm{KM}_{2}$ & $\%$ \\
\hline 1-Rio Tijuco & 15.928 & 30,1 \\
\hline 2 - Rio Arantes & 7.594 & 14,4 \\
\hline 3 - Rio Verde ou Feio & 7.197 & 13,7 \\
\hline 4-Rio Araguari & 7.146 & 13,5 \\
\hline 5-Rio Uberaba & 5.862 & 11,2 \\
\hline 6-Rio Piedade & 4.475 & 8,5 \\
\hline 7 - Rio São Francisco & 4.558 & 8,6 \\
\hline TOTAL & 52.760 & 100,0 \\
\hline
\end{tabular}

De acordo com os dados acima, a subbacia do Rio Tijuco é a que ocupa maior área, $15.928 \mathrm{Km}^{2}$, sendo responsável pela drenagem de $30,1 \%$ da área de estudo. Seu principal afluente é o rio da Prata. A menor área é dominada pela sub-bacia do rio Piedade, com $4.475 \mathrm{Km}^{2}$. Os rios Tijuco, Arantes, Araguari e Piedade, afluentes do rio Paranaíba, são responsáveis pela drenagem de $66,5 \%$ da área do Triângulo Mineiro.

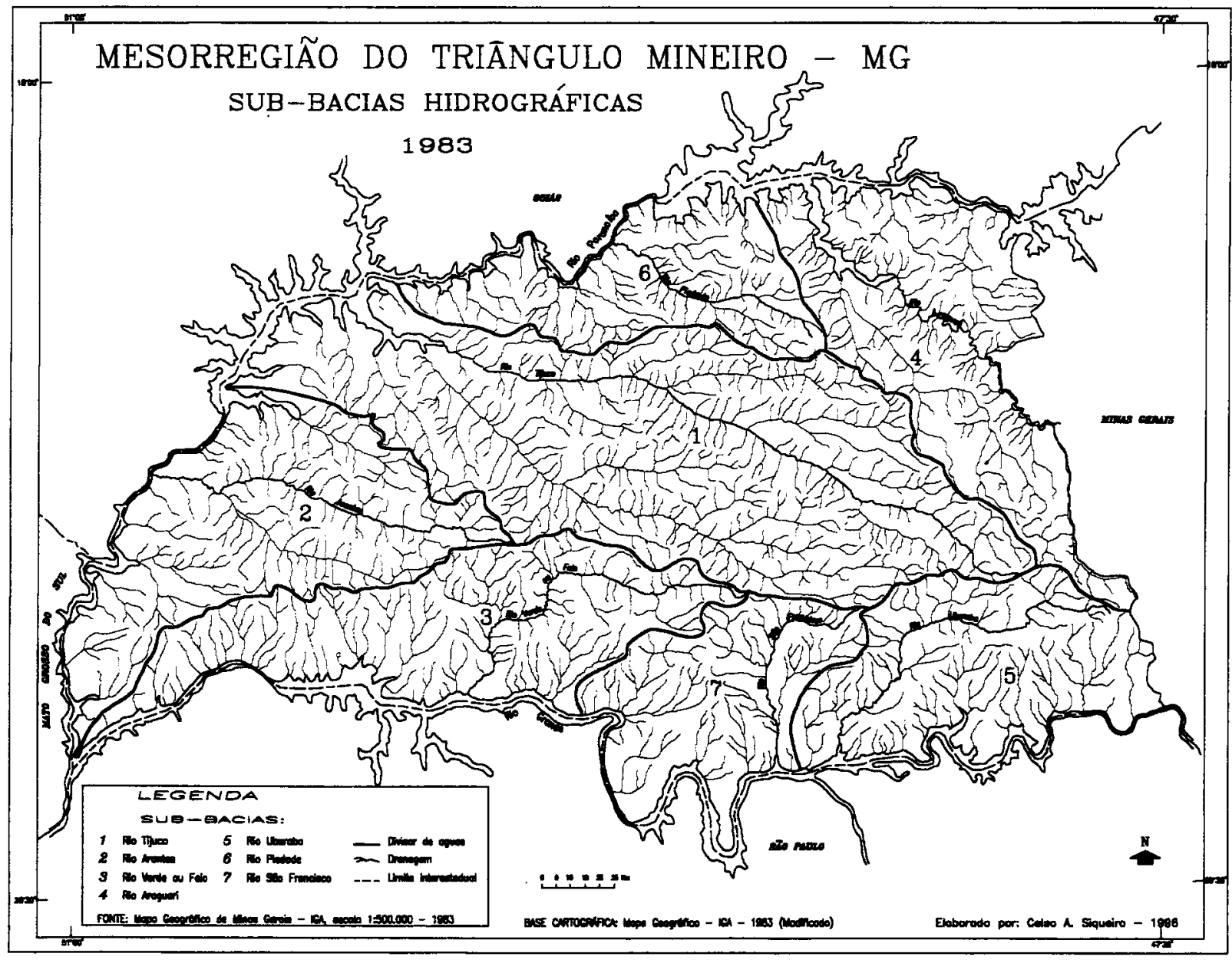




\section{3 - Geologia}

Segundo OLIVEIRA (1993), este é um mapa especial que representa, sob a forma de símbolos e cores qualitativas, os diferentes tipos de rochas ou ainda as idades dos terrenos.

As informações do mapa geológico foram parcialmente compiladas de trabalhos anteriores e adaptadas à base, na escala de 1:500.000. O objetivo desse mapeamento é o de proceder a uma delimitação das unidades geológicas presentes na área de estudo. Desta forma, estão nele representados somente os três grandes grupos de rochas, classificados de acordo com a sua origem, que são: rochas sedimentares, rochas vulcânicas e rochas metamórficas (Quadro 3, Mapa 3, em anexo)

Quadro 3 - área ocupada pelas diferentes categorias geológicas

\begin{tabular}{|l|c|c|}
\hline \multicolumn{1}{|c|}{ Categorias } & $\mathbf{K m}^{2}$ & $\%$ \\
\hline Rochas sedimentares & 36.768 & 69,7 \\
\hline Rochas vulcânicas & 13.573 & 25,7 \\
\hline Rochas metamórficas & 2.419 & 4,6 \\
\hline \multicolumn{1}{|c|}{ TOTAL } & 52.760 & 100,0 \\
\hline
\end{tabular}

Observa-se que no Triângulo Mineiro predominam as rochas sedimentares, que ocupam a maior parte da sua área interior, ou seja, $36.768 \mathrm{~km}^{2}$, o que representa $69,7 \%$ da

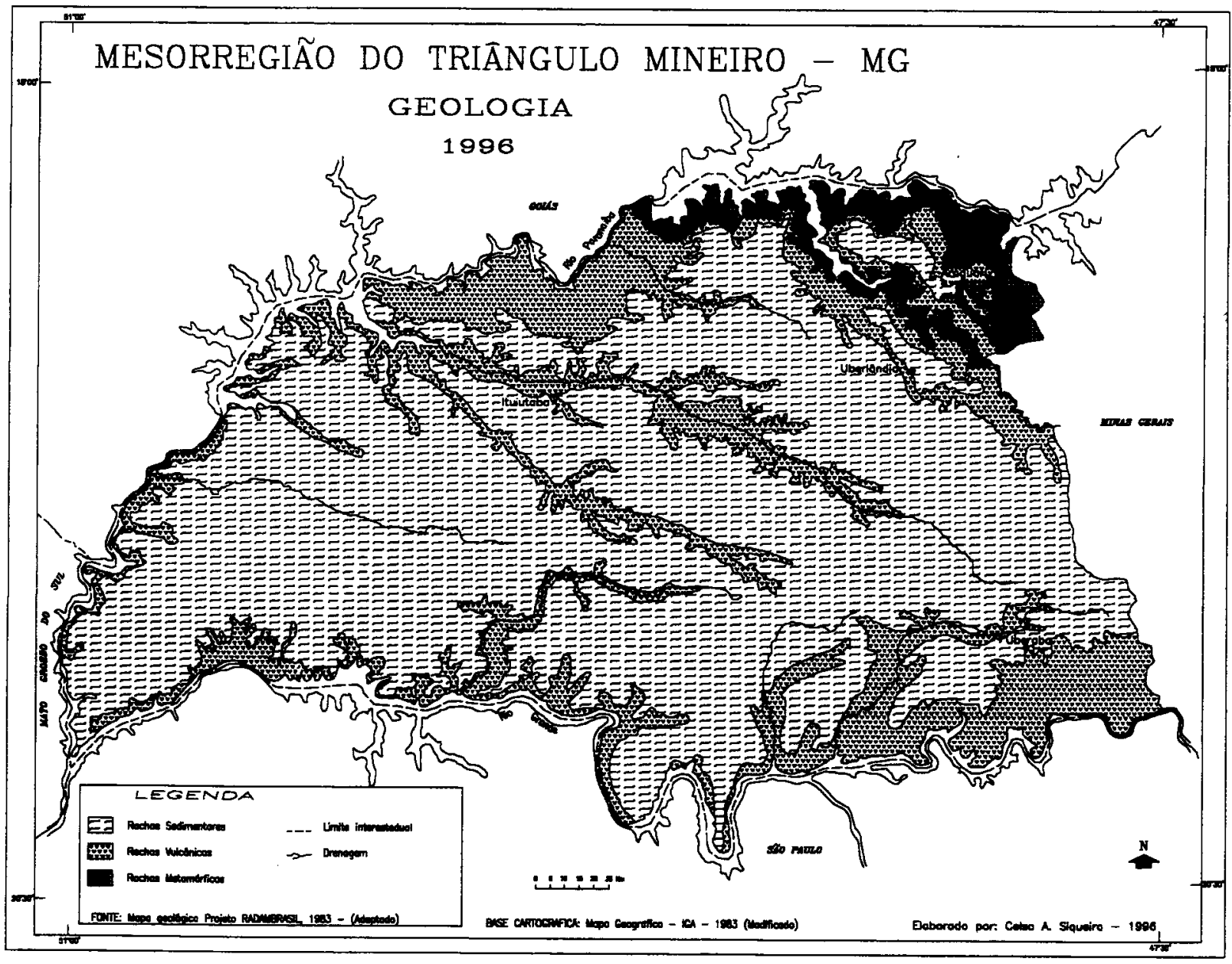

Sociedade \& Natureza, Uberlândia, 10 (19): 93-114, janeiro/junho 1998 
área de estudo. As rochas vulcânicas, representadas pelo basalto, ocupam $25,7 \%$ da área de estudo e são encontradas ao longo dos principais canais de drenagem, como os rios Tijuco, Prata, Araguari, Uberaba, Verde ou Feio, com maior expressão nos vales dos rios Grande e Paranaíba. Já as rochas metamórficas ocupam $2.419 \mathrm{~km}^{2}$, uma pequena faixa da porção nordeste da área de estudo, que representa $4,6 \%$ da área total.

\section{4 - Geomorfologia}

É um mapa temático de síntese, que representa as formas do relevo segundo as suas dimensões, tipos, gênese e relações com a estrutura dinâmica (OLIVEIRA, 1993).

Segundo ROSA (1995), a forma do relevo é de fundamental importância no estudo das paisagens. As informações topográficas são indispensáveis, devendo ser representadas de forma precisa, clara, simples e por meio de uma simbologia elaborada de modo a aproximar-se ao máximo das formas existentes no espaço geográfico e a facilitar a sua leitura e interpretação. Devem também ser quantificadas, de modo a permitir a avaliação e interpretação correta do modelado.

Este mapa também foi compilado e adaptado à base de 1:500.000. Para a definição das suas categorias, levou-se em consideração a dimensão espacial da forma, o aprofundamento dos canais de drenagem e a declividade das vertentes, deduzidos previamente através da análise de imagens de satélite, chegando-se então à definição de cinco categorias, que são: área de chapada, áreas de relevo pouco dissecado, áreas de relevo dissecado, áreas de relevo residual e áreas de planície fluvial, (Quadro 4, Mapa 4).

Quadro 4 - Área ocupada pelas diferentes categorias geomorfológicas

\begin{tabular}{|l|r|r|}
\hline \multicolumn{1}{|c|}{ Categorias } & $\mathrm{Km}^{2}$ & $\%$ \\
\hline Área de Chapada & 1.940 & 3,7 \\
\hline Área de relevo pouco dissecado & 40.376 & 76,5 \\
\hline Área de relevo dissecado & 7.272 & 13,8 \\
\hline Área de relevo residual & 2.507 & 4,7 \\
\hline Área de planície fluvial & 665 & 1,3 \\
\hline \multicolumn{1}{|c|}{ TOTAL } & 52.760 & 100 \\
\hline
\end{tabular}




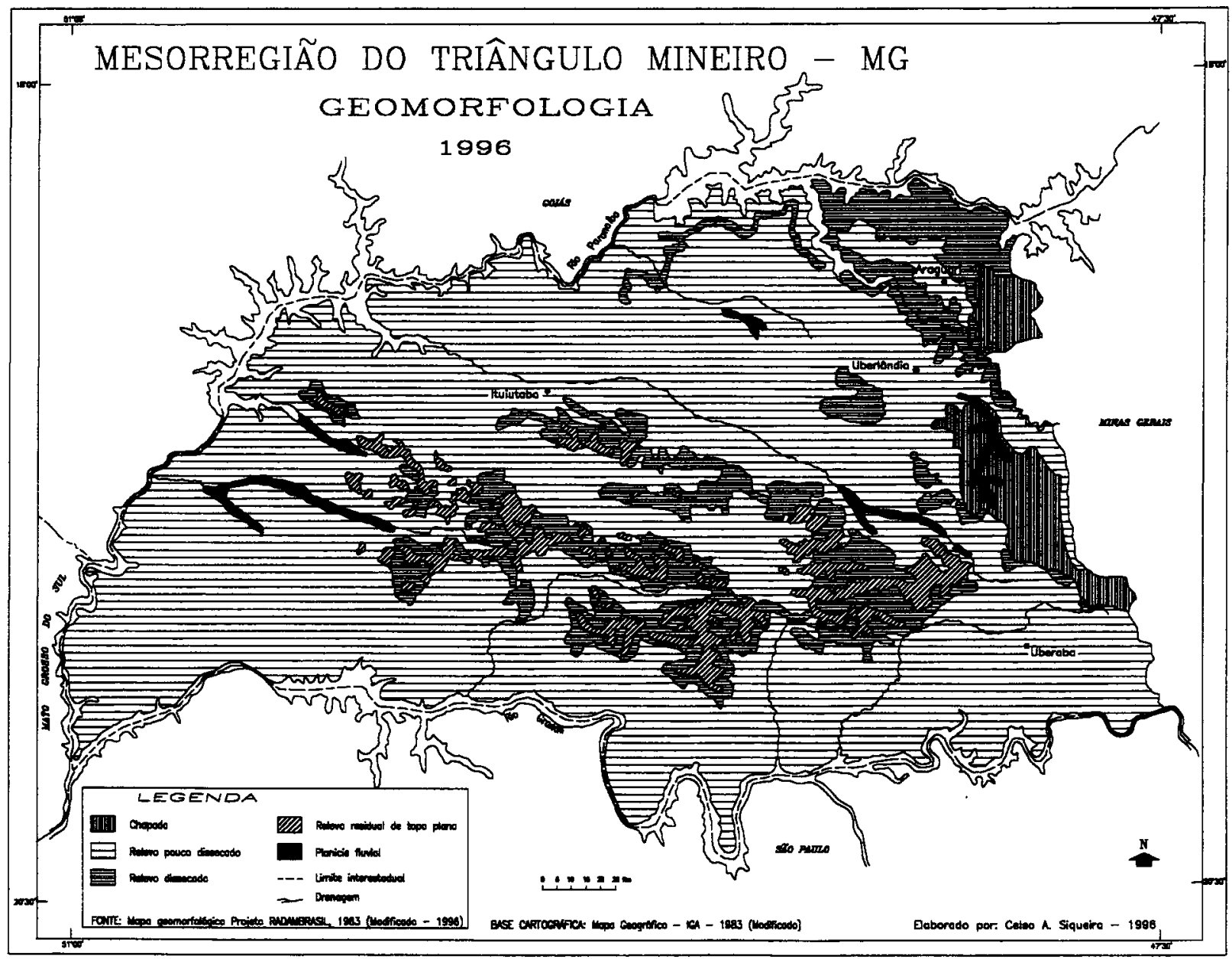

\section{5 - Hipsometria}

De acordo com OLIVEIRA (1993), hipsometria é o meio pelo qual se determinam as altitudes da Terra em relação ao nível do mar. Portanto, mapa hipsométrico é aquele que representa o terreno ou o relevo submarino em termos de altitude, acima ou abaixo de um plano de referência, seja em curvas, em sombreado ou em cores.

Segundo ROSA (1995), a hipsometria preocupa-se principalmente com o estudo das interrelações existentes numa determinada unidade horizontal de espaço, referindo-se à sua distribuição em relação às cotas altitudinais, indicando a proporção ocupada por determinada área da superfície terrestre em relação às variações altimétricas a partir de determinada isoipsa base. Além disto, a hipsometria possibilita, através de um maior conhecimento, verificar o índice de dissecação de um relevo, sabido que sua interferência é decisiva no processo erosivo, sobretudo através do escoamento superficial da água.

As informações do mapa hipsométrico foram compiladas de trabalhos existentes no 
laboratório de geoprocessamento e adaptadas à base cartográfica especialmente elaborada para esse fim. Neste mapa estão delineadas curvas de nível com 200 metros de equidistância, a partir das quais definiu-se pela iden- tificação de quatro categorias, que são: áreas com altitudes inferiores a $400 \mathrm{~m}$, áreas com altitudes entre 400 e $600 \mathrm{~m}$, áreas com altitudes entre 600 e $800 \mathrm{~m}$ e áreas com altitudes superiores a $800 \mathrm{~m}$ (Quadro 5, Mapa 5).

Quadro 5 - Área ocupada pelas diferentes categorias altimétricas

\begin{tabular}{|c|c|c|}
\hline Categorlas & $\mathrm{Km}^{2}$ & $\%$ \\
\hline$<400 \mathrm{~m}$ & 3.609 & 6,8 \\
\hline $400-600 \mathrm{~m}$ & 26.409 & 50,1 \\
\hline $600-800 \mathrm{~m}$ & 17.255 & 32,7 \\
\hline$>800 \mathrm{~m}$ & 5.487 & 10,4 \\
\hline TOTAL & 52.760 & 100,0 \\
\hline
\end{tabular}

Analisando o quadro 5 e o mapa 5, verifica-se que a categoria mais representativa refere-se às áreas situadas entre 400 e $600 \mathrm{~m}$ de altitude, com $26.409 \mathrm{~km}^{2}$, correspondente a

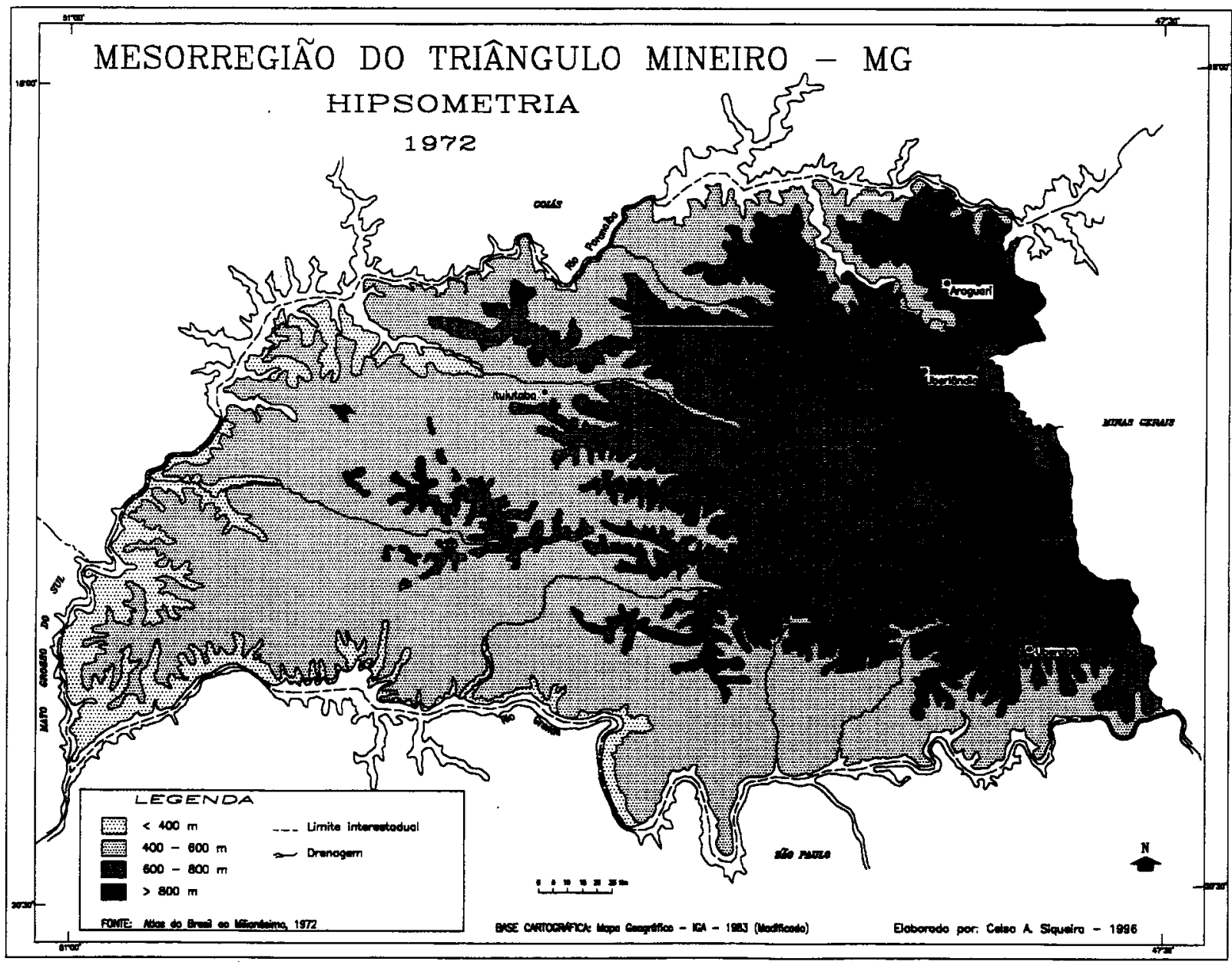


$50,1 \%$, ocupando as porcões norte, sudeste e centro-oeste do Triângulo Mineiro. Outros $17.255 \mathrm{~km}^{2}$, ou $32,7 \%$, correspondem às áreas com altitudes entre 600 e 800 , situadas na porção centro-leste da área de estudo. As áreas situadas acima de 800 metros, somando 5.487 $\mathrm{km}^{2}$, correspondem às áreas de chapada, com topo plano, situadas a leste da região. Já as áreas situadas abaixo dos 400 metros, somando $3.609 \mathrm{~km}^{2}$, ou $6,8 \%$, referem-se aos terrenos mais baixos, que se encontram às margens dos rios Paranaíba e Grande, em suas porções noroeste, oeste e sudoeste, mais expressivamente próximo a área de confluência dos citados rios.

\section{6 - Declividade}

Segundo ROSA (1995), a erosão do solo tem-se transformado em um dos grandes problemas para a expansão da agricultura brasileira. O mapa de declividade do terreno, quando devidamente correlacionado a outros tipos de fenômenos topográticos, constitui-se num importante instrumento de apoio aos estudos de potencialidade de uso agrícola de uma determinada área.

A escolha das categorias de um mapa de declividade depende do objetivo do estudo e também da escala em que se trabalha. No presente estudo, em função da escala (1:500.000) não possibilitar um maior nivel de detalhamento, optou-se por definir as seguintes categorias: áreas com declividade fraca; áreas com declividade moderada $e$ as áreas com declividade forte (Quadro 6, Mapa 6).

Na sua elaboração procedeu-se a uma análise e adaptação das classes do mapa geomorfológico, utilizando-se também as folhas topográficas editadas pelo IBGE, na escala de 1:250.000, com curvas de nível eqüidistantes $50 \mathrm{~m}$, para cálculo das porcentagens que englobam cada categoria.

Quadro 6 - Área ocupada pelas diferentes categorias de inclinação do relevo

\begin{tabular}{|l|r|r|}
\hline \multicolumn{1}{|c|}{ Categorias } & $\mathrm{Km}^{2}$ & $\%$ \\
\hline Declividade Fraca & 4.422 & 8,4 \\
\hline Declividade Moderada & 41.078 & 77,8 \\
\hline Declividade Forte & 7.260 & 13,8 \\
\hline \multicolumn{1}{|c|}{ TOTAL } & 52.760 & 100,0 \\
\hline
\end{tabular}




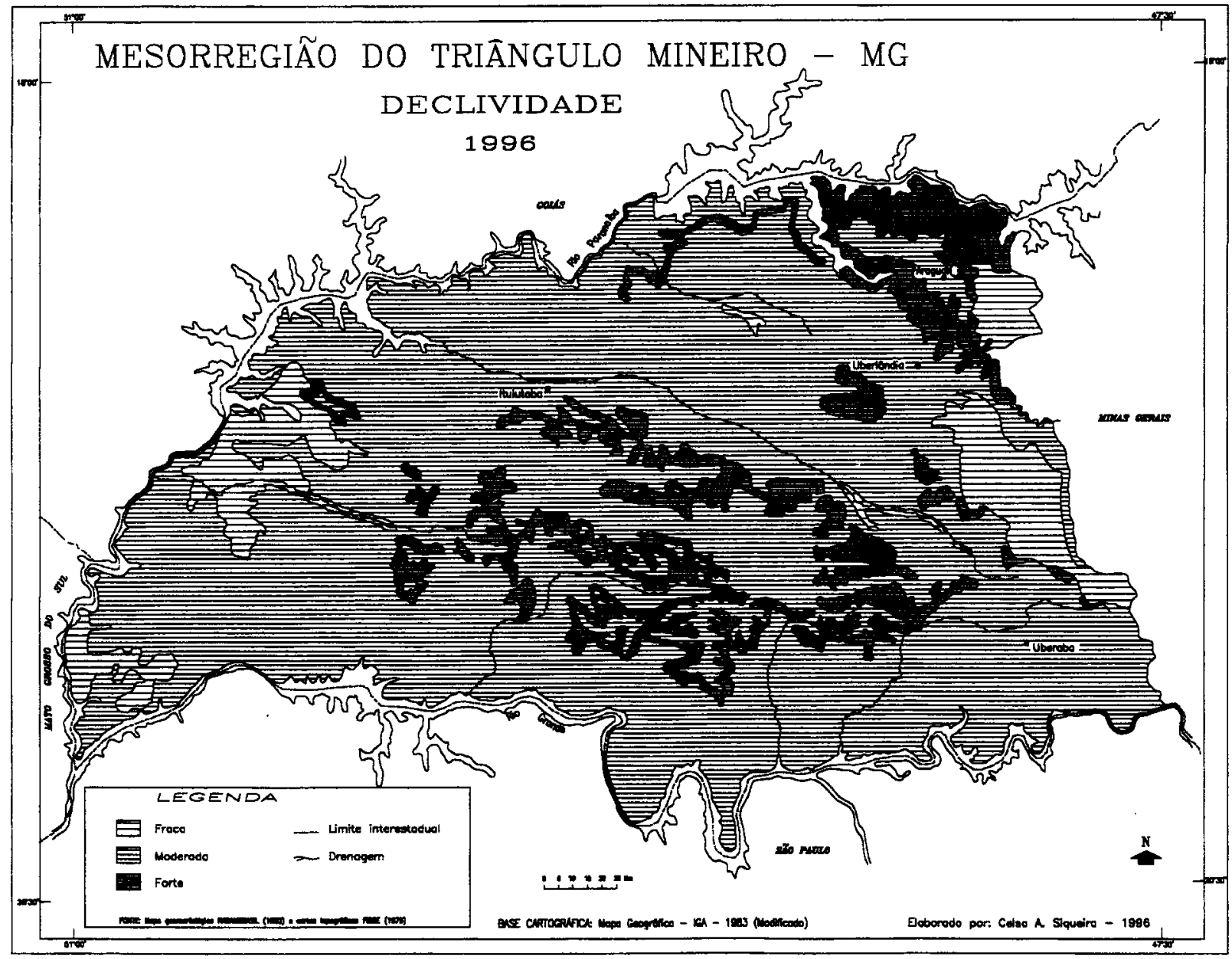

\section{7 - Solos}

De acordo com LEPSCH (1993), solo "é a massa natural que compõe a superfície da terra, que suporta ou é capaz de suportar plantas", ou ainda "a coleção de corpos naturais que contém matéria viva e é resultante da ação do clima (...) sobre a rocha, cuja transformação em solo se realiza durante certo tempo e é influenciado pelo tipo de relevo".

O solo constitui-se em um recurso natural de grande importância, principalmente por dar suporte aos vegetais, dos quais depende a vida humana. Por isso é fundamental o conhecimento dos vários tipos de solos existentes, as suas caracteristicas, os principais elementos que o constituem e também os fatores naturais responsáveis pela sua formação. $O$ conhecimento do solo permite prevenir vários tipos de erosão, além de propor o uso adequado para cada tipo de solo. Alguns fatores são responsáveis pela existência dos diferentes tipos de solos, e basicamente são: clima, natureza dos organismos, material de origem, relevo e idade da superfície do terreno.

Segundo LEPSCH (1993), o mapa pedológico, ou de solos, é geralmente elaborado para mostrar a distribuição e a 
delimitação das áreas de dominância das diversas classes de solos, utilizando-se como base uma carta com a localização de alguns acidentes geográficos, tais como os rios, as estradas e as cidades. Vale ressaltar que, de uma forma geral, as diversas classes representadas nos mapas de solos raramente apresentam limites rigidos. Ao contrário, é comum a existência de uma faixa e não de uma linha de transição entre os diversos tipos de solos, transição esta que acontece gradualmente.
Esse mapa também foi compilado de trabalhos anteriores, cujas principais informações foram extraídas do mapa de solos do Projeto RADAMBRASIL - Folha SE-22 Goiânia, na escala de 1:1.000.000 e adaptadas ao mapa base, na escala de 1:500.000. Nele estão identificadas oito categorias: Latossolo Vermelho-Escuro álico, Latossolo VermelhoAmarelo álico, Latossolo Vermelho-Escuro distrófico, Latossolo Roxo distrófico e eutrófico, Podzólico Vermelho-Amarelo distrófico e eutrófico, Cambissolo álico e eutrófico, Glei Húmico álico e distrófico, e Areia Quartzosa álica (Quadro 7, Mapa 7).

Quadro 7 - Área ocupada pelos diferentes tipos de solos

\begin{tabular}{|c|c|c|}
\hline 9 & $\mathrm{Km} \mathrm{m}^{2}=$ & $0 . \%$ \\
\hline Latossolo Vermelho-Escuro álico & 32.253 & 61,1 \\
\hline Latossolo Vermelho-Amarelo álico & 1.661 & 3,2 \\
\hline Latossolo Vermelho-Escuro distrófico & 3.189 & 6,0 \\
\hline Latossolo Roxo distrófico e eutrófico & 10.188 & 19,3 \\
\hline Podzólico Vermelho-Amarelo distrófico e eutrófico & 3.016 & 5,7 \\
\hline Cambissolo álico e eutrófico & 1.278 & 2,4 \\
\hline Glei Húmico álico e distrófico & 797 & 1,6 \\
\hline Areia Quartzosa álica & 378 & 0,7 \\
\hline TOTAL & 52.760 & 100,0 \\
\hline
\end{tabular}


O quadro 8 apresenta as principais no mapa de solos. características das categorias representadas

Quadro 8 - Principais características dominantes dos solos mapeados

\begin{tabular}{|c|c|c|c|c|c|}
\hline solo & $\begin{array}{c}\text { HORIZONTE } \\
\text { CARACTERÍSTICO }\end{array}$ & $\begin{array}{l}\text { Cor } \\
\text { DoMINANTE }\end{array}$ & TEXTURA & IrTolocis & RELEVO \\
\hline Lea & B latossólico & $2,5 Y R$ & média & Arenito & $\begin{array}{c}\text { Plano e suave } \\
\text { ondulado } \\
\end{array}$ \\
\hline Lva & B latossólico & $2,5 Y R$ & média & Arenito & $\begin{array}{c}\text { Plano e suave } \\
\text { ondulado }\end{array}$ \\
\hline Led & A fraco a moderado & 2,5YR & muito argilosa & Arenito & Ondulado \\
\hline $\begin{array}{l}\text { LRd } \\
\text { Lre }\end{array}$ & B latossólico & 2,5YR e 10YR & $\begin{array}{c}\text { argilosa a muito } \\
\text { argilosa } \\
\end{array}$ & basalto & $\begin{array}{c}\text { Plano e suave } \\
\text { ondulado } \\
\end{array}$ \\
\hline $\begin{array}{l}\text { PVd } \\
\text { Pve }\end{array}$ & B textural & 5YR e 10YR & argilosa & arenito & $\begin{array}{c}\text { Suave } \\
\text { ondulado a } \\
\text { Forte } \\
\text { ondulado } \\
\end{array}$ \\
\hline $\begin{array}{l}\mathrm{Ca} \\
\mathrm{Ce}\end{array}$ & B câmbico & 5YR e 2,5YR & média & variadas & $\begin{array}{c}\text { Suave a } \\
\text { Forte } \\
\text { ondulado }\end{array}$ \\
\hline $\begin{array}{l}\mathrm{HGHa} \\
\mathrm{HGHd}\end{array}$ & $\begin{array}{l}\text { A chernozênico ou } \\
\text { proeminente }\end{array}$ & $\begin{array}{c}\text { cinza a preto } \\
\text { (horizonte } \\
\text { superficial) }\end{array}$ & $\begin{array}{c}\text { areno-argilosa } \\
\text { heterogênea }\end{array}$ & $\begin{array}{c}\text { Sedimentos } \\
\text { areno-argilosos } \\
\text { de depósitos } \\
\text { aluvionares } \\
\text { holocênicos } \\
\end{array}$ & Plano \\
\hline Aqa & A - C seqüencial & 2,5YR e $5 Y R$ & arenosa & arenito & $\begin{array}{c}\text { Plano e suave } \\
\text { ondulado } \\
\end{array}$ \\
\hline
\end{tabular}




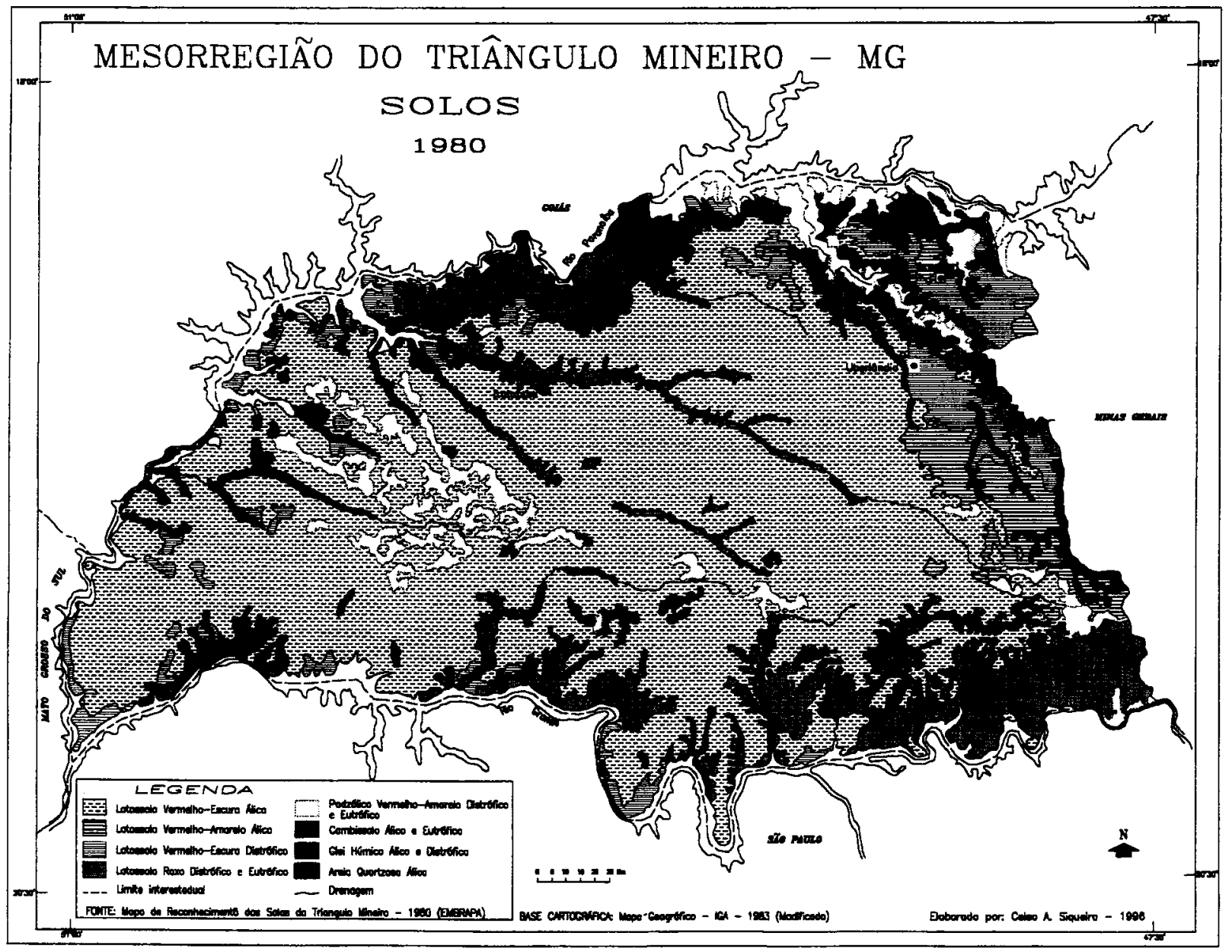

\section{8 - Temperatura Média Anual}

É um mapa coroplético, representando a variação da temperatura média anual na Mesorregião do Triângulo Mineiro, ou seja, corresponde à média aritmética das temperaturas mensais registradas no ano. Para sua elaboração foram definidas seis categorias: áreas que apresentam temperatura média anual menor que $20^{\circ} \mathrm{C}$, entre 20 e $21^{\circ} \mathrm{C}$, entre $21 \mathrm{e}$ $22^{\circ} \mathrm{C}$, entre 22 e $23^{\circ} \mathrm{C}$, entre 23 e $24^{\circ} \mathrm{C}$ e áreas com média anual superior a $24^{\circ} \mathrm{C}$ de temperatura (Quadro 9, Mapa 8). 
Mapeamento Digital dos Aspectos Físicos da Mesorregião do Triângulo Mineiro, Através dos Softwares Autocard12 $e$ Grass 4.0, Celso Antônio de Siqueira, Roberto Rosa

Quadro 9 - Área ocupada pelas diferentes categorias de temperatura média anual

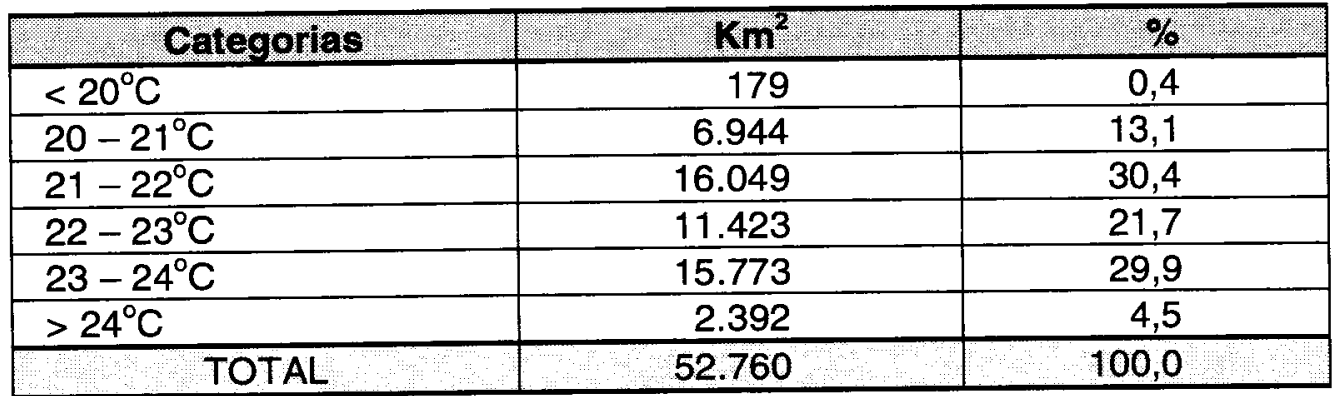

A variação da temperatura está diretamente ligada às diferentes altitudes da região, que ajudam a definir as áreas com maiores e menores temperaturas, ou seja, quanto maior a altitude menor a temperatura ou relação inversa. Observa-se que a área com

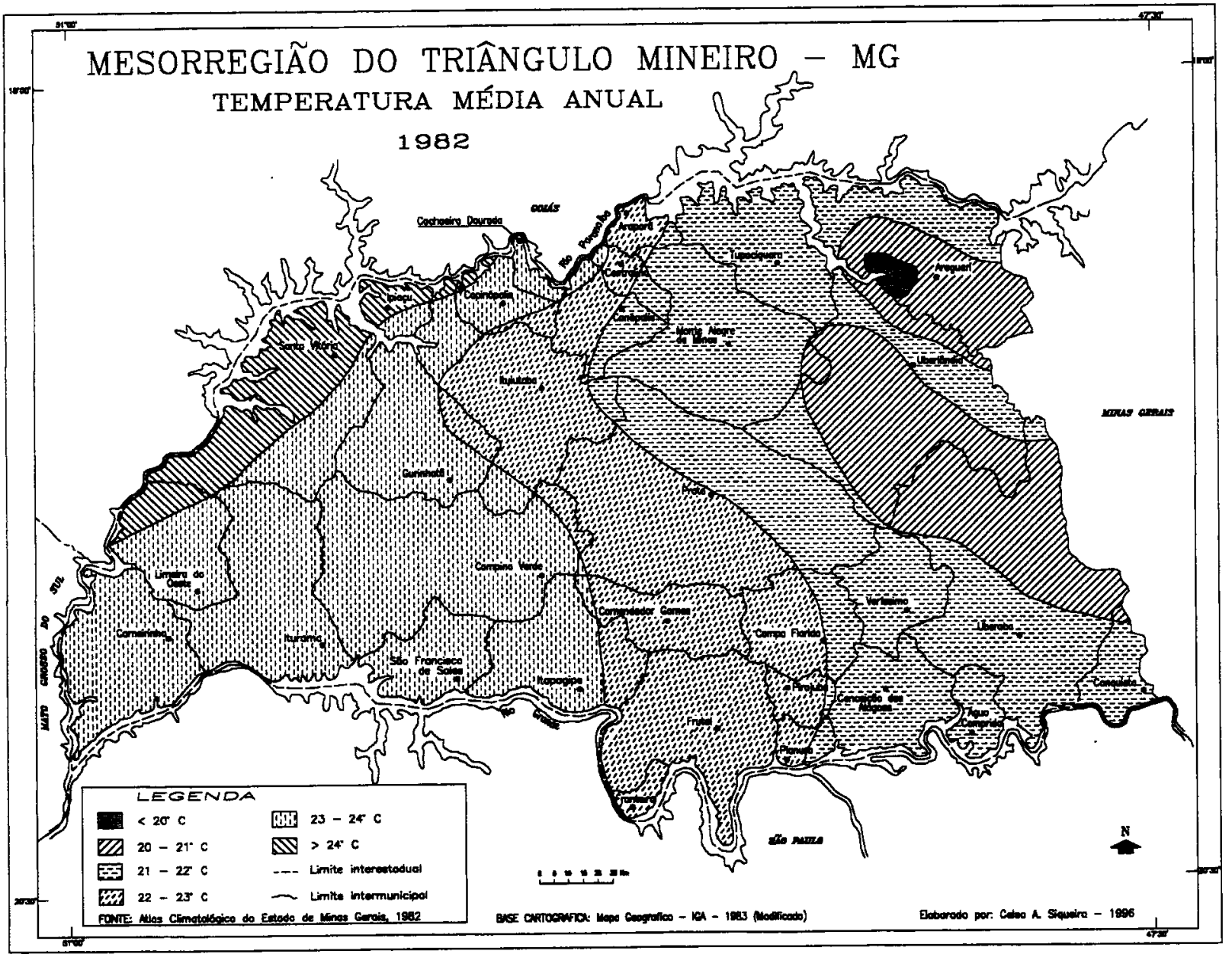


temperatura média anual mais elevada $\left(24^{\circ} \mathrm{C}\right)$ está situada a noroeste do Triângulo Mineiro, em locais próximos ao Rio Paranaíba, com altitudes menores que $400 \mathrm{~m}$ e outras com altitudes que variam de 400 a $600 \mathrm{~m}$, abrangendo parte dos municípios de Ipiaçu, Santa Vitória e uma faixa do município de Limeira do Oeste. A maior faixa, com temperatura média anual entre 21 e $22^{\circ} \mathrm{C}$, abrange as cidades de Uberlândia, Uberaba, Tupaciguara, Canápolis, Monte Alegre, Veríssimo, Conceição das Alagoas, Água Comprida e Conquista. Uma pequena mancha, situada próximo à cidade de Araguari, entre 600 e $800 \mathrm{~m}$, é a área que apresenta a menor temperatura média anual ( $<$ $\left.20^{\circ} \mathrm{C}\right)$.

\section{9 - Precipitação Anual}

É também um mapa coroplético, representando a média de precipitação anual da área de estudo. Nele estão identificadas quatro categorias: áreas com precipitação anual menor que $1400 \mathrm{~mm}$, entre 1400 e $1500 \mathrm{~mm}$, entre 1500 e $1600 \mathrm{~mm}$ e áreas com precipitação anual superior a $1600 \mathrm{~mm}$ (Quadro 10, Mapa 9).

Quadro 10 - Área ocupada pelas diferentes categorias de precipitação anual

\begin{tabular}{|c|c|c|}
\hline Categorias & $\mathrm{Km}^{2}$ & $\%$ \\
\hline$<1400 \mathrm{~mm}$ & 14.029 & 26,6 \\
\hline $1400-1500 \mathrm{~mm}$ & 12.781 & 24,2 \\
\hline $1500-1600 \mathrm{~mm}$ & 25.181 & 47,7 \\
\hline$>1600 \mathrm{~mm}$ & 769 & 1,5 \\
\hline TOTAL & 52.760 & 100,0 \\
\hline
\end{tabular}

A categoria mais importante e representativa é a que envolve as áreas com precipitação anual entre 1500 e $1600 \mathrm{~mm}$, que ocupam $25.181 \mathrm{Km}^{2}$ ou $47,7 \%$, correspondendo a uma grande área do Pontal, abrangendo os municípios de Santa Vitória,
Limeira do Oeste, Carneirinho, Iturama, Campina Verde, Comendador Gomes, São Francisco de Sales, Frutal, Itapagipe e Fronteira e uma faixa mais estreita a leste da região, abrangendo os municípios de Uberlândia, Uberaba e Conquista. 


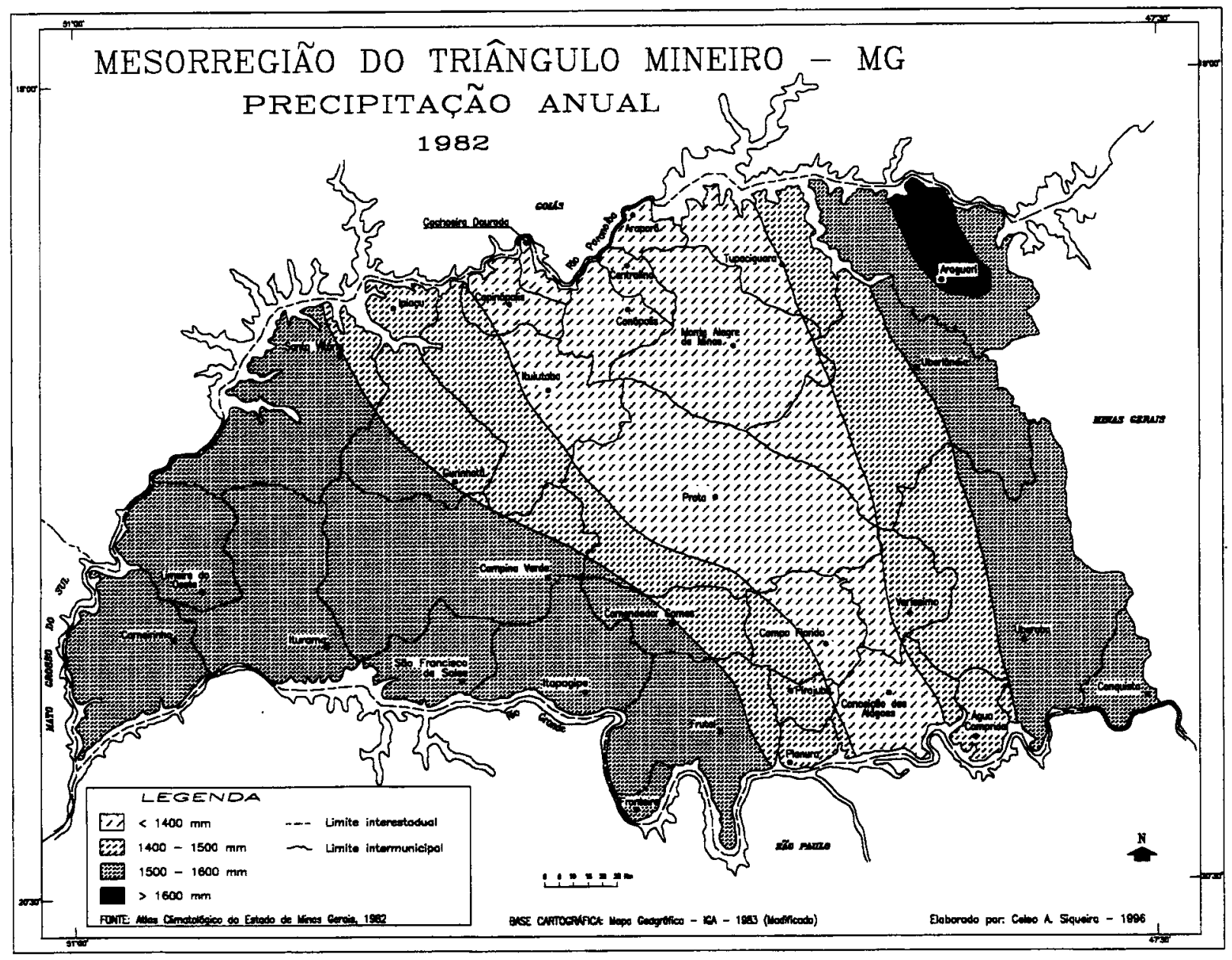

\subsection{0 - Uso da Terra}

Segundo ROSA (1995), a expressão "uso da terra" refere-se à forma pela qual se dá a ocupação do espaço pelo homem. A importância do mapeamento do uso da terra diz respeito à possibilidade de identificação de uma série de efeitos provocados pelo uso desordenado do solo, cujas conseqüências podem ser sérias e imediatas, como por exemplo os processos erosivos, as inundações e assoreamentos de reservatórios e de cursos d'água, que causam grande deterioração no ambiente.
Desta forma, por tratar de aspectos fundamentais para a compreensão dos padrões de organização do espaço, é necessário que os mapeamentos de uso da terra sejam constantemente atualizados, de modo a permitir uma análise mais fiel e freqüente de suas tendências. Nesse contexto, o sensoriamento remoto constitui-se em uma técnica de grande utilidade pois permite, em curto espaço de tempo, a obtenção de uma grande quantidade de informações a respeito de registros de uso da terra (ROSA, 1995).

De acordo com ANDERSON et alii (1979) apud ROSA (1995), não existe uma 
classificação única e ideal para os tipos de revestimento e uso da terra. Cada classificação é feita de forma a atender às necessidades do usuário e adaptada à região. O mapa de uso da terra foi elaborado através da análise de imagens de satélite TM/Landsat, optando-se inicialmente pela identificação de alguns padrões baseados nas diferenças de cor, textura, forma, tamanho, geralmente associados aos aspectos de relevo e drenagem, que ajudam a diferir a vegetação. Em função da escala de apresentação do mapa, definiuse pelo mapeamento das seguintes categorias: mata/cerradão/cerrado, pastagem/campo limpo/campo sujo, reflorestamento, cultura, área urbana/uso misto (Quadro 11, Mapa 10 ).

Quadro 11- Área ocupada pelas diferentes categorias de uso da terra

\begin{tabular}{|l|r|r|}
\hline \multicolumn{1}{|c|}{ Categorlas } & \multicolumn{1}{|c|}{$\mathrm{Km}^{2}$} & $\%$ \\
\hline Mata / Cerradão / Cerrado & $5.445,6$ & 10,32 \\
\hline Pastagem / Campo limpo / Campo sujo & $34.518,7$ & 65,42 \\
\hline Reflorestamento & $1.069,3$ & 2.03 \\
\hline Culturas & $11.478,3$ & 21,76 \\
\hline Áreas Urbanas / Uso misto & 248,1 & 0.47 \\
\hline \multicolumn{1}{|c|}{ TOTAL } & $52.760,0$ & 100,00 \\
\hline
\end{tabular}

O quadro 12 apresenta uma tabulação cruzada de dados que propicia a análise da predominância das diferentes categorias do mapa de uso da terra, sobre as categorias dos mapas de declividade e de solos, a partir da sobreposição dos mesmos, feita através do software GRASS 4.0.

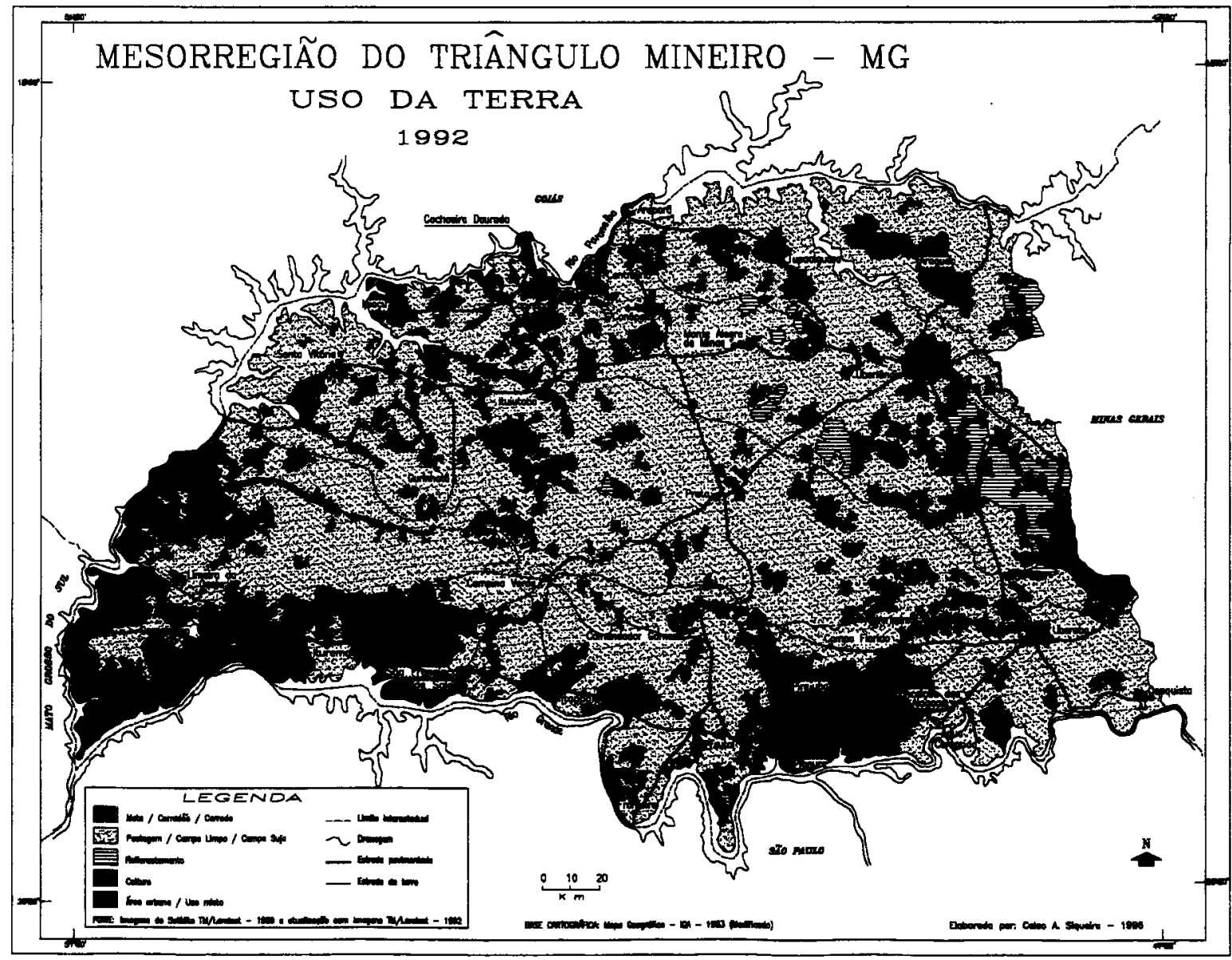

Sociedade \& Natureza, Uberlândia, 10 (19): 93-114, janeiro/junho 1998 
Quadro 12 - Tabulação cruzada dos mapas Uso da Terra x Declividade x Solos

\begin{tabular}{|c|c|c|c|c|c|c|c|c|c|c|c|c|c|c|c|c|}
\hline & 6 & $\mid \begin{array}{l}\infty \\
\infty\end{array}$ & $\stackrel{\mathscr{E}}{=}$ & $\stackrel{\mathbb{R}}{-1}$ & $\mid$\begin{tabular}{l|}
5 \\
$55^{\circ}$
\end{tabular} & 䓂 & 悉 & & & & \begin{tabular}{|l|l|}
8 \\
0
\end{tabular} & $\overline{3}$ & & & r & \\
\hline & $\sqrt{\xi}$ & $\begin{array}{l}+ \\
\infty \\
\infty\end{array}$ & $\mid \begin{array}{l}\mathscr{g} \\
\end{array}$ & $\hat{\sigma}$ & $\begin{array}{ll}2 \\
8 \\
\end{array}$ & 多 & के & & & & \begin{tabular}{|l|l} 
\\
15
\end{tabular} & 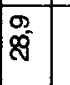 & & & ' & \\
\hline 9 & 10 & $\begin{array}{l} \\
\mathbb{Z}\end{array}$ & 8 & \begin{tabular}{|l|l|}
8 \\
\end{tabular} & R & \begin{tabular}{|l|}
$\mathscr{8}$ \\
0 \\
\end{tabular} & $\div$ & 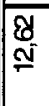 & $\frac{\nabla}{10}$ & $\begin{array}{l}\mathrm{N} \\
\stackrel{\mathrm{S}}{ }\end{array}$ & \begin{tabular}{|l|l|}
8 \\
0 \\
\end{tabular} & ס্ & & & & \\
\hline s & 5 & $\mid \frac{n}{ \pm}$ & $\mid \begin{array}{l}\infty \\
\not{m}\end{array}$ & 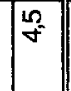 & 赵 & 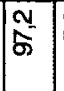 & 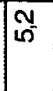 & $\begin{array}{l} \\
8\end{array}$ & $\stackrel{9}{9}$ & $\underset{N}{\Delta}$ & $\begin{array}{l}0 \\
8 \\
8\end{array}$ & 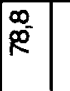 & & & 1' & \\
\hline 8 & $\int^{8}$ & & \begin{tabular}{|l|}
$\mathscr{R}$ \\
$\mathrm{N}$
\end{tabular} & $\mid$ & 客 & $\stackrel{q}{\prime}$ & $\frac{N}{=}$ & & & & 8 & \begin{tabular}{|l|l}
58 \\
8
\end{tabular} & $\begin{array}{l}\mathbb{N} \\
\mathcal{J}^{\prime}\end{array}$ & & 8 & \\
\hline 8 & $\sqrt{\xi}$ & & 8 & $\stackrel{\mathscr{N}}{\mathbb{N}}$ & 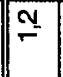 & $\overline{\mid \overline{6}}$ & $\overline{6}$ & & ' & ' & 8 & $\overline{5}$ & 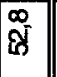 & & $\bar{\nabla}$ & \\
\hline$?$ & {$[\sqrt{2}$} & 8 & 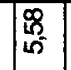 & 它 & 8 & 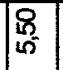 & $\mid \begin{array}{l}\infty \\
\infty \\
\infty\end{array}$ & & 1 & ' & \begin{tabular}{|l|l|}
$g$ & \\
\end{tabular} & \begin{tabular}{|l|l}
$\frac{15}{0}$ & 8 \\
0 & 9 \\
\end{tabular} & $\begin{array}{l}8 \\
9 \\
9\end{array}$ & & 11 & \\
\hline 8 & $\sqrt{E}$ & 2 & 品 & $\mid \begin{array}{l}\tilde{R} \\
\end{array}$ & $\stackrel{2}{=}$ & 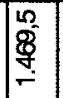 & : & & & ' & $\cong$ & \begin{tabular}{|l|l}
$g$ & 0 \\
$N$ & 0
\end{tabular} & \begin{tabular}{|l|}
$g$ \\
$g$
\end{tabular} & & & \\
\hline 9 & 110 & 8 & $\mid \begin{array}{l}8 \\
\infty \\
\infty\end{array}$ & $\frac{10}{6}$ & 8 & \& & 8 & $\underset{-1}{\mathbb{8}}$ & $\ddot{m}$ & ' & 8 & $\begin{array}{l}\mathbb{8} \\
\bar{m}\end{array}$ & $\begin{array}{l}8 \\
\pm \\
\end{array}$ & & \begin{tabular}{l}
60 \\
\multirow{A}{*}{}
\end{tabular} & $\begin{array}{l}F \\
8 \\
8\end{array}$ \\
\hline 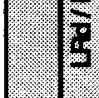 & 5 & 票 & 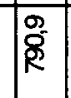 & $\mid$\begin{tabular}{l}
$\infty$ \\
\multirow{\sigma}{*}{}
\end{tabular} & 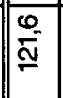 & 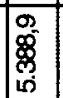 & 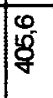 & $\stackrel{\text { Na }}{=}$ & $\stackrel{\infty}{\infty}$ & ${ }^{\prime}$ & 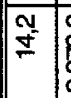 & 筩 & \&ृ & & 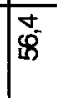 & $\stackrel{-}{0}$ \\
\hline & 28 & sి & 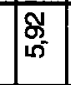 & $\frac{m}{0}$ & \begin{tabular}{|l|}
8 \\
$\infty$ \\
$\infty$ \\
0
\end{tabular} & N & $\stackrel{8}{-}$ & 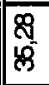 & $\begin{array}{l}8 \\
15 \\
15\end{array}$ & ' & \begin{tabular}{l|l}
9 \\
0 \\
8
\end{tabular} & 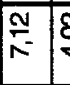 & 8 & & $\begin{array}{l} \\
\bar{\sigma} \\
\end{array}$ & \\
\hline 9 & 5 & 10 & $\frac{2}{\sqrt{2}}$ & 8 & \begin{tabular}{|l|}
$\infty$ \\
$\frac{\infty}{5}$ \\
$\frac{1}{m}$
\end{tabular} & 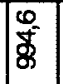 & \&্ষ & 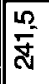 & :̊̀ & 1 & $\frac{5}{m}$ & $\left.\begin{array}{|l|}0 \\
0 \\
0 \\
6\end{array}\right]$ & $\begin{array}{l} \\
\\
\\
\end{array}$ & & 응 & \\
\hline & 8 & $\stackrel{8}{\circ}$ & 胥 & $\begin{array}{l}0 \\
\stackrel{2}{N} \\
\text { N }\end{array}$ & 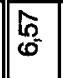 & $\stackrel{\mathbb{N}}{=}$ & 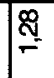 & $\begin{array}{l}8 \\
8 \\
F\end{array}$ & $\begin{array}{l}\infty \\
0 \\
0\end{array}$ & 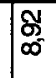 & $\begin{array}{l}\mathbb{N} \\
\dot{A}\end{array}$ & \begin{tabular}{|l|}
$g$ \\
s
\end{tabular} & 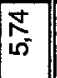 & & $\begin{array}{l}8 \\
0\end{array}$ & \\
\hline & $\sqrt{2}$ & 然 & :్̊ㅁ & $\frac{10}{N}$ & 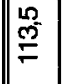 & ָू & 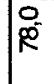 & बे & ज্মি & 守 & $\bar{E}$ & 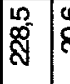 & 8ू & & 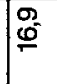 & \\
\hline & 8 & 蒿 & 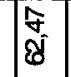 & $\mid \begin{array}{l}\mathbb{R} \\
\mathbb{R}\end{array}$ & 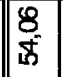 & \begin{tabular}{|l|}
8 \\
8 \\
6
\end{tabular} & $\frac{8}{8}$ & $\stackrel{\mathbb{S}}{\mathrm{d}}$ & 若 & 8 & $\mid \begin{array}{l}\bar{\infty} \\
\overline{8} \\
\bar{b}\end{array}$ & \begin{tabular}{|l|}
\multirow{O}{*}{} \\
$\sigma$
\end{tabular} & \begin{tabular}{|l|} 
\\
6 \\
6
\end{tabular} & & $\begin{array}{l}8 \\
80 \\
80\end{array}$ & $\begin{array}{l}\mathbb{E} \\
8\end{array}$ \\
\hline 9 & 5 & \begin{tabular}{|l|l}
$\infty$ \\
$\mathbb{N}$ \\
$\mathbb{N}$
\end{tabular} & $\mid \frac{n}{8}$ & $\mid$ & 赵 & 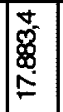 & 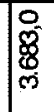 & $\begin{array}{l}\infty \\
\infty\end{array}$ & 吾 & $\underset{\infty}{\infty}$ & $\begin{array}{l}\infty \\
8 \\
8 \\
8\end{array}$ & 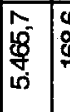 & 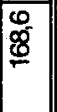 & & \begin{tabular}{|l|} 
\\
8
\end{tabular} & $\stackrel{0}{\circ}$ \\
\hline & $\because 8$ & $\mathbb{P}$ & $\mid \begin{array}{l}\hat{a} \\
\stackrel{0}{O}\end{array}$ & $\left|\begin{array}{l|}R \\
O \\
O\end{array}\right|$ & $\begin{array}{l}8 \\
8\end{array}$ & 恋 & 8 & 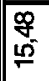 & 尺ू. & $\overline{\bar{\delta}}$ & $\begin{array}{l}8 \\
\overline{5}\end{array}$ & \begin{tabular}{|l|l|}
$\frac{0}{2 \pi}$ & \\
\end{tabular} & 昰 & & $\bar{\varnothing}$ & 8 \\
\hline$\sqrt{3}$ & $\sqrt{2}$ & 品 & $\overline{\overline{z ্ ষ ্ ণ ~}}$ & $\mid$\begin{tabular}{l|}
$\infty$ \\
0 \\
0 \\
$k$
\end{tabular} & 急 & 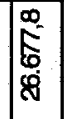 & $\begin{array}{l}1 \\
88 \\
80 \\
0\end{array}$ & 尔 & 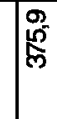 & ম্ম & $\mid \begin{array}{c}0 \\
\overline{6} \\
\stackrel{6}{*}\end{array}$ & \begin{tabular}{|l|}
0 \\
$\frac{1}{10}$ \\
$\sigma$
\end{tabular} & \begin{tabular}{|l|}
8 \\
8 \\
8
\end{tabular} & & $\begin{array}{l}\mathscr{S} \\
\stackrel{5}{a}\end{array}$ & $\begin{array}{l}\text { N } \\
\text { w }\end{array}$ \\
\hline & 8 & 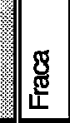 & 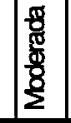 & \begin{tabular}{|l} 
竞 \\
\end{tabular} & \begin{tabular}{|l}
$\mathbb{8}$ \\
$\mathbb{E}$
\end{tabular} & 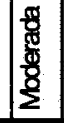 & 帝 & $\mid \underset{\mathbb{4}}{\mathbb{E}}$ & $\mid \begin{array}{l}\text { 要 } \\
\frac{1}{8} \\
\frac{1}{2}\end{array}$ & 离 & (I) & \begin{tabular}{|l|}
$\frac{8}{8}$ \\
$\frac{8}{80}$ \\
$\frac{8}{8}$ \\
\end{tabular} & 离 & $\mid$\begin{tabular}{|ll}
$\mathbb{8}$ \\
$\mathbb{2}$
\end{tabular} & 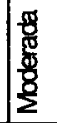 & 离 \\
\hline $\begin{array}{l}\frac{8}{6} \\
\frac{6}{8} \\
8 \\
8\end{array}$ & $\sqrt{3}$ & 通 & $\begin{array}{l}\text { 稀 } \\
\overline{8}\end{array}$ & $\frac{8}{8}$ & 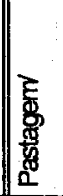 & $\begin{array}{l}\frac{8}{2} \\
\frac{5}{3} \\
\frac{8}{8} \\
\end{array}$ & 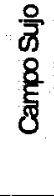 & & 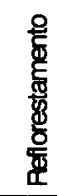 & & & 急 & & & $\begin{array}{l}\frac{5}{8} \\
\frac{8}{5} \\
\frac{8}{8}\end{array}$ & \\
\hline
\end{tabular}


A análise do quadro 12 permite as seguintes observações:

- a categoria Mata/Cerradão/Cerrado, do mapa de uso da terra, predomina em áreas de declividade moderada, ocupando 4.260,1 $\mathrm{Km}^{2}$ ou $10,37 \%$ da área total representada por esta categoria no mapa de declividade. Do total acima, $67,47 \%$ ou $2.661,5 \mathrm{Km}^{2} \mathrm{da}$ categoria Mata/Cerradão/Cerrado encontram-se em áreas onde predomina 0 Latossolo Vermelho-Escuro álico.

- a categoria Pastagem/Campo limpo/Campo sujo, do mapa de uso da terra, ocupa $26.677,8 \mathrm{~km}^{2}$ ou $64,94 \%$ do total correspondente às áreas de declividade moderada do mapa de declividade. Deste total, $67,05 \%$ ou $17.883,4 \mathrm{Km}^{2}$ da categoria Pastagem/Campo limpo/Campo sujo encontram-se sobre o Latossolo VermelhoEscuro álico.

- a categoria Reflorestamento, do mapa de uso da terra, predomina em áreas de declividade fraca, ocupando $684,5 \mathrm{Km}^{2}$ ou $15,48 \%$ da área representada por esta categoria no mapa de declividade. Do total referido, $322,4 \mathrm{Km}^{2}$ ou $47,83 \%$ da categoria Reflorestamento situam-se em áreas de predomínio do Latossolo Vermelho-Amarelo álico.

- a categoria Cultura, do mapa de uso da terra, ocupa $9.517,6 \mathrm{Km}^{2}$ ou $23,16 \%$ do total correspondente às áreas de declividade moderada do mapa de declividade. Deste total, $5.465,7 \mathrm{Km}^{2}$ ou $57,42 \%$ da categoria Cultura encontram-se sobre o Latossolo Vermelho-Escuro álico.

- a categoria Área Urbana/Uso Misto, do mapa de uso da terra, predomina em áreas de declividade moderada, ocupando 246,6 $\mathrm{Km}^{2}$ ou $0,61 \%$ da área representada por esta categoria no mapa de declividade. Do total referido, $103,0 \mathrm{Km}^{2}$ ou $41,76 \%$ da categoria Área Urbana/Uso Misto situam-se em áreas de predomínjo do Latossolo Vermelho-Escuro distrófico.

\section{6 - CONSIDERAÇÕES FINAIS}

Analisando-se os mapas e os números das áreas ocupadas pelas diferentes categorias de cada tema representado verifica-se, por exemplo, que a sub-bacia do Rio Tijuco é a maior e a mais extensa, e também que a área de estudo caracteriza-se, em termos gerais, pela predominância das rochas sedimentares, das áreas de relevo pouco dissecado e de declividade moderada, pela presença do Latossolo Vermelho-Escuro álico e pelas imensas áreas de Pastagem/campo limpo/ campo sujo. Nota-se ainda a predominância das áreas com altitude entre 400 e $600 \mathrm{~m}$, da temperatura média anual entre 21 e $22^{\circ} \mathrm{C}$ e de uma média de precipitação anual entre 1500 e $1600 \mathrm{~mm}$.

A utilização dos computadores e de acessórios como mesa digitalizadora, plotters, etc., auxiliados por softwares específicos, representa um enorme avanço para a cartografia, possibilitando a criação de arquivos de armazenamento, permitindo a atualização das informações, ou ainda a alteração de cores, escala, acrescentar ou eliminar um nível ou camada identificada de representação (layer). Além disto, pode-se calcular a área e o perímetro de um determinado polígono representado em um mapa, resultando numa produção incomparavelmente mais rápida e de qualidade final muito melhor.

Neste trabalho, devido às limitações apresentadas pelo software AutoCAD, no que concerne à execução de cálculo de área em polígonos com contornos muito irregulares, utilizou-se o software GRASS 4.0, que é um SIG - Sistema de Informação Geográfica, para efetuação de tais cálculos. Apesar disto, o software AutoCAD possui um grande número de funções que possibilitam a representação precisa de dados e informações geográficas. 
A dinâmica de evolução e desenvolvimento de novos equipamentos e softwares, criam recursos para os quais parece não existir fronteiras. Para as pessoas que se enveredaram pelo mundo contagiante dos computadores, os caminhos do "fazer", "realizar", "produzir" talvez se encurtem; no entanto, o do "conhecer" parece inesgotável, pois o domínio dos variados programas existentes, em sua totalidade de opções e funções, se não é impossível, é uma tarefa bastante complexa, exigindo disciplina e muita dedicação.

Finalizando, concluiu-se que a metodologia utilizada alcançou bons resultados para o fim proposto, levando a afirmar que, apesar das limitações já colocadas anteriormente, - AutoCAD é um software bastante útil na digitalização e apresentação de mapas.

\section{7 - REFERÊNCIAS BIBLIOGRÁFICAS}

Anuário Estatístico de Minas Gerais 1990-1993. Belo Horizonte, Fundação João Pinheiro. V8, 1994. 760p.

ASSAD, E. D. \& SANO, E. E. Sistema de Informações Geográficas: aplicações na agricultura. Planaltina: EMBRAPA-CPAC, 1993. 274p.

BACCARO, C. A. D. Estudos geomorfológicos do município de Uberlândia. Sociedade \& Natureza. Uberlândia. EDUFU 1(1): 17-21, Junho 1989.

As unidades Geomorfológicas e a Erosão nos Chapadões do Município de Uberlândia. Sociedade \& Natureza. Uberlândia. EDUFU, 6 (11 e 12): 19-33, Jan/Dez 1994.

BRITO, J. L. S. \& ROSA, R. Introdução aos Sistemas de Informação Geográfica. Sociedade \& Natureza. Uberlândia. EDUFU 6(11-12): 61-78, Jan/Dez. 1994.
CENSI, A. L. C., LADEIRA, M. C. \& LIMA, C. C. N. A. AutoCAD 12: guia prático. São Paulo: Érica, 1994.

CINTRA, J. P. CAD, GIS, DBMS ou Cartografia Digital? Coletânea de trabalhos técnicos XV Congresso Brasileiro de Cartografia. Vol. 2. São Paulo. 1991. pp. 343-348.

FERREIRA, C. C. \& SIMÕES, N. N. Tratamento Estatístico e Gráfico em Geografia. 2a. Ed. Lisboa. Gradiva, 1987.

JOLY, F. A Cartografia. Campinas - SP : Papirus, 1990.

LAKATOS, E. M. \& MARCONI, M. A. Metodologia do Trabalho Científico: procedimentos básicos, pesquisa bibliográfica, projeto $e$ relatório, publicações e trabalhos científicos. $4^{\mathrm{a}}$ ed. São Paulo : Atlas, 1992.

LEINZ, V. \& AMARAL, S. E. Geologia Geral. São Paulo. Companhia Editora Nacional. 1985.

LEITE, W. J. S. Aprendendo AutoCad 12 para DOS. São Paulo : Érica, 1994.

LEPSCH, I. F. Solos: formação e conservação. $5^{\text {a }}$ ed. São Paulo: Melhoramentos, 1993 (Prisma).

LIMA, M. \& NEVES, R. R. O mapa como meio de comunicação. Anais do XIV Congresso Brasileiro de Cartografia, Vol. 2. Gramado. 1989. pp. 359-364.

LIMA, S. C. As veredas do Ribeirão Panga e a Evolução do Relevo do Triângulo Mineiro. São Paulo. Departamento de geografia. FFCL-USP. (Tese de Doutoramento) 1996, $260 \mathrm{p}$.

MATHER, P. M. Computer Applications in Geography. Chichester : John Wiley \& Sons. 1994. pp 100-139. 
NISHIYAMA, L. Geologia do Município de Uberlândia e áreas adjacentes. Sociedade \& Natureza. Uberlândia. EDUFU 1(1): 09-16, Junho 1989.

OLIVEIRA, C. Curso de cartografia moderna. 2ed. Rio de Janeiro : IBGE. 1993.

Dicionário Cartográfico. 4ed. Rio de Janeiro : IBGE. 1993.

OLIVEIRA, I. S. AutoCAD 12 - aplicações. São Paulo : Érica, 1993.

PARAGUASSU, A. B., GANDOLFI, N. \& LANDIM, P. M. B. Curso Prático de Geologia Geral. São Carlos. 1974.

PETRI, S. \& FÚLFARO, V. J. Geologia do Brasil. São Paulo : T. A. Queiroz : Ed. da Universidade de São Paulo, 1983.

RADAMBRASIL. Levantamento de recursos naturais. Ministério das Minas e Energia. Folha SE-22/Goiânia, vol. 31, Rio de Janeiro, 1983. 768p.

ROSA, R. Considerações acerca de uma metodologia de interpretação de dados TM/ Landsat. Sociedade \& Natureza. Uberlândia. EDUFU, 2(4): 97-110, 1990.

Caracterização Fisiográfica do Município de Araguari. Sociedade \& Natureza. Uberlândia. EDUFU, 4(7/8): 53-75, 1992.

O uso de SIG's para o zoneamento: uma abordagem metodológica. São Paulo. FFLCH/USP, 1995. (Tese de Doutoramento)

TAYLOR, D. R. Fraser, The computer in Contemporary Cartography. John Wiley \& Sons : Canadá, 1980. (Progress in Contemporary Cartography, Vol. I). 